\title{
Comparative Analysis of Human Coronaviruses Focusing on Nucleotide Variability and Synonymous Codon Usage Pattern
}

\author{
Jayanta Kumar Das ${ }^{\mathrm{a}, *}$, Swarup Roy ${ }^{\mathrm{b}, *}$ \\ ${ }^{a}$ Department of Pediatrics, School of Medicine, Johns Hopkins University, MD-21205, USA \\ ${ }^{b}$ Network Reconstruction $\mathcal{E}$ Analysis (NetRA) Lab, Department of Computer Applications, Sikkim University, Gangtok, India
}

\begin{abstract}
Prevailing pandemic across the world due to SARSCoV-2 drawing great attention towards discovering its evolutionary origin. We perform an exploratory study to understand the variability of the whole coding region of possible proximal evolutionary neighbours of SARSCoV-2. We consider seven (07) human coronavirus strains from six different species as a candidate for our study.

First, we observe a good variability of nucleotides across candidate strains. We did not find a significant variation of GC content across the strains for codon position first and second. However, we interestingly see huge variability of GC-content in codon position 3rd (GC3), and pairwise mean GC-content (SARSCoV, MERSCoV), and (SARSCoV2, hCoV229E) are quite closer. While observing the relative abundance of dinucleotide feature, we find a shared typical genetic pattern, i.e., high usage of GC and CT nucleotide pair at the first two positions (P12) of codons and the last two positions (P23) of codons, respectively. We also observe a low abundance of CG pair that might help in their evolution bio-process. Secondly, Considering RSCU score, we find a substantial similarity for mild class coronaviruses,i.e., hCoVOC43, hCoVHKU1, and hCoVNL63 based on their codon hit with high RSCU value ( $\geq 1.5)$, and minim number of codons hit (count-9) is observed for MERSCoV. We see seven codons ATT, ACT, TCT, CCT, GTT, GCT and GGT with high RSCU value, which are common in all seven strains. These codons are mostly from Aliphatic and Hydroxyl amino acid group. A phylogenetic tree built using RSCU feature reveals proximity among hCoVOC43 and hCoV229E (mild). Thirdly, we perform linear regression analysis among GC content in different codon position and ENC value. We observe a strong correlation (significant p-value) between GC2 and GC3 for SARSCoV-2, hCoV229E and hCoVNL63, and between GC1 and GC3 for hCoV229E, hCoVNL63, SARSCoV. We believe that our findings will help in understanding the mechanism of human coronavirus.
\end{abstract}

Keywords: Nucleotide, Codon, RSCU, ENC, Amino acid, Correlation, Phylogeny, Human Coronavirus

\section{Introduction}

Coronavirus is a large enveloped virus (familyCoronaviridae, subfamily-Coronavirinae) with nonsegmented, single-stranded, and positive-sense RNA genomes [1]. Among many, six coronaviruses have been known to infect human hosts and cause respiratory diseases. The SARS (Severe Acute Respiratory Syndrome) and MERS (Middle East Respiratory Syndrome) are the most lethal coronaviruses. SARSCoV is the first reported in China (2002) [2,3], which causes around two thousand deaths worldwide. MERSCoV is

\footnotetext{
*Corresponding Author

Email addresses: jdas4@jhmi.edu (Jayanta Kumar Das ), sroy01@cus.ac.in (Swarup Roy )
}

reported in Saudi Arabia (2012) and South Korea (2015) $[4,5]$. In a timeline, SARSCoV-2 is the recently reported coronavirus (2019), which provoked a large-scale epidemic, COVID-19, originated from Whung, the largest metropolitan area in China's Hubei province. Even then the diseases they are responsible for are quite different. COVID-19 has a strong infection power due to its high dissemination rate across the worldwide. According to WHO report ${ }^{1}$, more than six hundred thousand people are already dead so far (as on July 15, 2020) due to COVID-19. All these three groups of coronaviruses are highly pathogenic that resulted global outbreaks. The other three human coronaviruses are Human coronavirus OC43 (hCoVOC43), Human coronavirus HKU1

\footnotetext{
${ }^{1}$ https://www.worldometers.info/coronavirus/
} 
(hCoVHKU1), Human coronavirus 229E (hCoV229E) and Human coronavirus NL63 ( $h$ CoVNL63). They are categorized as mild due to its low infection and mortally rate.

From the genetic composition view point, the complete genome length of SARSCoV, SARSCoV-2, and MERSCoV is approximately $27-30 \mathrm{~kb}$. The genome of SARSCoV-2 showing quite high similarity $(\approx 79 \%)$ to SARSCoV and moderate similarity $(\approx 50 \%)$ to MER$\mathrm{SCoV}[6]$. A number of putative coding regions are available in SARSCoV-2 that encodes important genes that includes nonstructural proteins such as orflab, structural proteins namely spike glycoprotein $(\mathrm{S})$, envelope (E), membrane (M) and nucleocapsid (N), and several accessory protein chains [7, 2, 8, 9]. The two-thirds of the genome is at the $5^{\prime}$ side of the sequence, encoding the nonstructural proteins, and one-third are at the $3^{\prime}$ side encoding four structural proteins [7]. Coronavirus proteins play diverse functional role. Nonstructural proteins can block the host innate immune response [10]. Among many structural proteins, the envelope protein promotes viral assembly and release [11]. The spike proteins compose the spikes on the viral surface, binds to host receptors [11]. However, many of these sequence variability features of structural and nonstructural proteins are yet to investigate thoroughly.

The 20 standard amino acids are genetically coded by 64 codons, including 3 stop codons for translation termination signal [12]. Therefore, a single amino acid are coded by multiple codons, which are called synony- 104 mous codons. The number of synonymous codons is 105 varying between 1 to 6 . Virus genomes are differ from 106 each others due to frequent mutations that can prevent 107 the PCR primers bind to target sequences [13]. Muta- 108 tion plays a key role that triggered a zoonotic virus to 109 jump from animal host to humans[14] host. Due to sev- 110 eral other biological factors, such as pathogenicity the 111 range of target hosts also vary diversely even in closely 112 related strains $[15,16]$. Genome-wide codon usage sig- 113 nature can reflect evolutionary forces $[17,17]$. It has 114 been observed that the inter and intra-species codon us- 115 age patters are varying significantly [18] in different or- 116 ganisms. It is therefore genetically important to study 117 the nucleotide base composition in all the three posi- 118 tions of a codon, because nucleotide composition can 119 influence the codon usage and mutational bias [19, 20]. ${ }_{120}$ The frequency of dinucleotide feature is also impor- 121 tant that may affect codon usage [19]. In this context, 122 GC content in codons may be a good indicator towards 123 understanding expression of viral genes while interact- 124 ing inside human host cells [21, 22]. Previous studies 125 have demonstrated that usage of synonymous codon is 126 a non-random procedure $[23,24]$. The relative synonymous codon usage (RSCU) is used to standardize the codon usage of those amino acid encoded by multiple codons. The RSCU value is independent of the amino acid composition and has been used widely to estimate the codon usage bias. Several studies have been done on coronaviruses, mostly by focusing on independent genome $[25,19]$, different strains within the same genome [26], and host specific adaption and proximal origin of SARSCoV-2 virus [27, 28, 29]. The evolutionary mechanism of the SARSCoV, SARSCoV-2, MER$\mathrm{SCoV}$, including its mutation rate, have been studied, although several crucial roles are yet to known, especially SARSCoV-2 to fight with COVID19 disease. Therefore, a comparative study on human coronaviruses might be helpful to exploit crucial factors.

The current study have focused on comprehensive and integrated way of analysing of all known seven strains of human coronaviruses. Several bias indexing parameters have used such as nucleotide composition and dinucleotide odd ratio [30], synonymous codon usage pattern [31], effective number of codon usage $[32,33]$, and details are discussed in the following section.

\section{Materials and Methods}

\subsection{Data retrieval and filtering}

We took all six species of known human coronaviruses, a total of seven strains as one species is divided into two different strains. Human coronaviruses can broadly be divided into two classes based on their produced symptoms in humans, either potentially severe or mild. MERSCoV, SARSCoV and SARSCoV-2 are categorized into potentially severe class. Human coronavirus OC43 (hCoVOC43), Human coronavirus HKU1 (hCoVHKU1), Human coronavirus 229E (hCoV229E) and Human coronavirus NL63 (hCoVNL63) are categorized into mild condition class. Among, MERSCoV, SARSCoV, SARSCoV-2, hCoVOC43, hCoV229E are belonging to the Genus $\beta$-CoV, whereas hCoV229E and hCoVNL63 are belonging to the Genus $\alpha$-CoV.

Nucleotide sequences for each strain of length $\approx 28 \mathrm{~kb}$ are collected from NCBI database during April, 2020. At first, genome wise all the partial, incomplete, and duplicate sequence are removed. Then for each complete sequence, single coding sequences are obtained by concatenating coding region (i.e., codons) of all genes (that include nonstructural polyprotein: orflab, structural proteins: Spike (S), Envelope (E), Membrane (M), Nucleocapsid (N) and several accessories proteins: 
Table 1: The quantitative information for number of unique sequences and involved protein coding genes for all seven strains.

\begin{tabular}{lll}
\hline Strains & $\begin{array}{l}\text { \# unique } \\
\text { sequence }\end{array}$ & $\begin{array}{l}\text { \# protein } \\
\text { coding genes }\end{array}$ \\
\hline SARSCoV & 134 & 1766 \\
SARSCoV-2 & 401 & 4525 \\
MERSCoV & 233 & 2509 \\
hCoVOC43 & 157 & 1257 \\
hCoVHKU1 & 34 & 277 \\
hCoV229E & 29 & 225 \\
hCoVNL63 & 56 & 389 \\
\hline
\end{tabular}

Orf3a, Orf3b, Orf6, Orf7a, Orf7b, Orf8(a/b), Orf10) of ${ }^{173}$ length having $\geq 150 \mathrm{bp}$. The gene-wise final dataset, including the number of unique sequence count and associated coding gene, i.e., protein information are reported in Table 1, which are utilized in our subsequent analysis.

\subsection{Measuring indexes}

Quantifying nucleotide composition- The quantity of nucleotide base composition i.e. A, T, C and $\mathrm{G}$ in different codon positions 1st/2nd/3rd can be calculated based on frequency measure. The base composition and GC content at first, second, and third positions of synonymously variable sense codons which can potentially vary from 0 to 1 . The nucleotide composition of any nucleotide $X$ at position $p$ is calculated as follows:

$$
N_{X}(p)=\frac{f_{x}}{f_{A}+f_{T}+f_{C}+f_{G}}
$$

where $X \in\{A, T, C, G\}, \mathrm{p} \in 1,2,3$ and $f_{A}, f_{T}, f_{C}, f_{G}$ are the nucleotide frequencies at particular position $p$ for ${ }_{190}$ A, T, C and G respectively.

Similarly, we calculate pair nucleotide composition in a particular position $p$ as follows:

$$
N_{X Y}(p)=\frac{f_{x}+f_{y}}{f_{A}+f_{T}+f_{C}+f_{G}}
$$

where $X, Y \in\{A, T, C, G\}, \mathrm{p} \in 1,2,3$ and $f_{A}, f_{T}, f_{C}, f_{G}$ are the nucleotide frequencies at particular position $p$ for $\mathrm{A}$, T, C and G respectively.

Relative dinucleotide abundance- Dinucleotide frequency is often used to determine favourable or unfavourable dinucleotide pairs. The variation in the frequency of dinucleotide pairs may affect codon usage. The total possible dinucleotide combinations are 16 . The patterns of dinucleotide frequency indicate both selectional and mutational pressures. Relative Dinucleotide Abundance frequency is calculated using the following formula:

$$
D_{x y}=\frac{f_{x y}}{f_{x} f_{y}}
$$

where $f_{x}$ and $f_{y}$ represent the individual frequency of nucleotides $x$ and $y$ respectively, and $f_{x} y$ is the frequency of dinucleotides (xy) in the same sequence. We calculate relative dinucleotide frequency for the codon positions first and second as well as second and third. The ratio of the observed to expected dinucleotide frequency is known as the odds ratio. The value of the odds ratio indicates underrepresented, if the value is below 0.78 , and overrepresented, if the value is above 1.25 [30].

Relative synonymous codon usage (RSCU) patternRelative synonymous codon usage (RSCU) is the observed number of occurrences of codons divided by that expected if the usage of synonymous codons uniformly [31] (Equation 4). The RSCU is used to standardize the codon usage of those amino acid encoded by multiple codons. The RSCU value is independent of the amino acid composition and has been used widely to estimate the codon usage bias. The RSCU value greater than 1.0 is considered to be a positive codon usage bias, and the RSCU value is less than 1.0 is considered to be a negative codon usage bias. Thus, a higher RSCU value means that the codon is used more frequently.

$$
R S C U_{i, j}=\frac{X_{i, j}}{\frac{1}{n} \sum_{j=1}^{n_{i}} X_{i, j}}
$$

where $X_{i}$ is the number of occurrences of the $j t h$ codon for the $i$ th amino acid, which is encoded by $n_{i}$ synonymous codons.

Effective number of codon $(E N C)$ usage- The effective number of codon $(E N C)$ usage can be obtain by Equation $5[32,33]$.

$$
\hat{N}_{c}=2+\frac{9}{\hat{F}_{2}}+\frac{1}{\hat{F}_{3}}+\frac{5}{\hat{F}_{4}}+\frac{3}{\hat{F}_{6}}
$$

where $F_{i}$ denotes the average homozygosity for the class with $i$ synonymous codons. The $E N C$ value ranges from 20 to 61. An $E N C$ of 20 represents extreme bias as only one codon is used for each amino acid, and a value of 61 suggests that there is no bias. In contrast to the RSCU value, a higher $E N C$ value correlates to a weaker codon usage bias. An alternate approach for calculating the $E N C$ is based on the GC3 content given in Equation 6.

$$
N_{c}=2+s+\left\{29 /\left[s^{2}+(1-s)^{2}\right]\right\}
$$

\section{Results and Discussion}

\subsection{Variability of nucleotide composition}

The variability of nucleotide composition is shown by box plot in Figure 1. It is noted that strain wise 

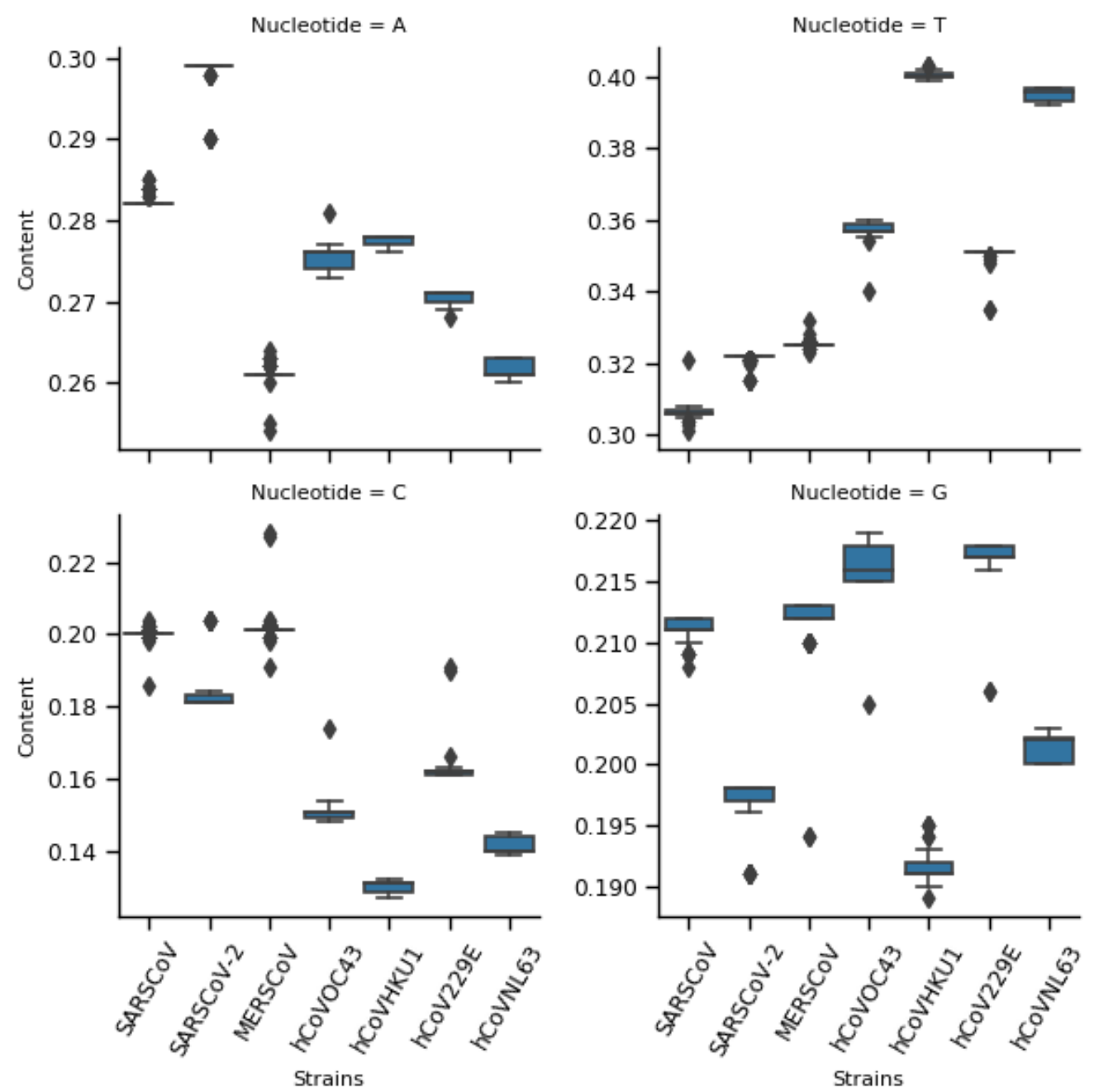

Figure 1: The box showing the distribution of $\mathrm{A} / \mathrm{T} / \mathrm{C} / \mathrm{G}$ content for seven strains of human coronaviruses.

nucleotide composition significantly differs, where base 222 composition for the MERSCoV genome is highly di- 223 verse for all nucleotide bases. Here, we focus a few high or low content of nucleotide composition for different 224 strains. We highlight each base of nucleotide content. 225 We observe that the content of A is high for SARSCoV- 226 2, and is low for MERSCoV and hCoVNL63; the con- 227 tent of $\mathrm{T}$ is high for hCoVHKU1 and hCoVNL63, and 228 is low for SARSCoV; the content of C is high for ${ }_{229}$ SARSCoV and MERSCoV, and is low hCoVHKU1; the 230 content of G is high for hCoVOC43 and hCoV229E, and ${ }_{231}$ is low for hCoVHKU1. General trends of CDSs of all ${ }_{232}$ coronavirus strains are shown to be rich in $\mathrm{A}$ and $\mathrm{T}\left(\approx{ }_{233}\right.$ 58-67\%-), in comparison to $\mathrm{G}$ and $\mathrm{C}$ nucleotide., with 234 the maximum is for hCoVHKU1 and minimum is for 235 MERSCoV. If $\mathrm{A}$ is high, then $\mathrm{T}$ is comparatively low ${ }_{236}$ and vice versa. This characteristic is similar to that of Nipah virus [19].

\subsection{Dinucleotide variability and usage pattern}

Dual-nucleotide (DN) composition and its variability are also essential as they represent the possible bonding nature and abundance of two consecutive nucleotides over the sequences. The occurrence of dinucleotide is important to study that directly play a role by impact on Codon usage bias, mutational bias and also the influence of selective pressure and compositional constraints. In RNA viruses, the relative abundance of dinucleotide has shown to affect codon usage [20]. We focus on both the first two codon position (P12) and the last two codon position (P23) for a quantitative measure of consecutive nucleotide pair, and the observed frequency distri- 
bution of nucleotide pair is shown in Figure 2. In the 286 present study, high abundance nucleotide pairs are AA, 287 GA, GT and TT for P12 as compared to high abundance 288 nucleotide pair AT, CT, GT and TT for P23. Among 289 these dinucleotides, GA and CT belong to purine and 290 pyrimidine group, respectively. We also observe less 291 variability of nucleotide pair across the strains for P23 292 compared to P12 (Figure 2). Overall, this indicates a 293 distinct pattern of nucleotide pairs in two consecutive 294 codon positions.

We measure the relative abundance of dinucleotide 296 content (odd ratio) as shown in Table 2. The top two 297 high and low usage dinucleotide pair is provided. Quan- 298 titatively, we observe a similar pattern for the highest 299 and lowest usage nucleotide pairs, which are GC and 300 CG, respectively, across the seven strains for P12. How- 301 ever, we find different structures for the second-highest 302 and lowest usage nucleotide pair. We also observe a ${ }_{303}$ distinct arrangement of high and low usage nucleotide 304 pairs for P23 across the strains and that is also different ${ }_{305}$ from the position P12 as stated above.

\subsection{GC-content usage pattern}

GC-content variability by the mean and standard deviation in three different positions ( $\mathrm{GC} 1, \mathrm{GC} 2, \mathrm{GC} 3)$ for seven strains of coronavirus is shown in Table 3, which is calculated using Eq. 2. We interestingly observe that GC3 shows high variability among seven strains, although the GC-content for GC1 and GC2 is much greater than that of GC3. Pairwise, mean GCcontent (SARSCoV, MSERCoV) and (SARSCoV-2, hCoV229E) are closer. We then look the position-wise GC-content distribution (Figure 3). It is observed that GC-content in three codon positions is well balanced for hCoVOC43 and SARSCoV-2 (mean difference $\approx$ 0.9). Whereas, hCoVHKU1 and hCoVNL63 show closer GC-content between the first and second positions of codon (mean difference; 0.9), and SARSCoV, MERSCoV and hCoV229E show closer GC-content between the second and third positions of codon (mean difference $<0.9$ )

\subsection{Synonymous codon usage pattern and phylogenetic clustering}

We obtain the RSCU values of 59-non trivial codons (Eq. 4). Strains-wise, RSCU value for each codon is shown in Table 4. RSCU value with a high score $(\geq 1.5) \quad 332$ is highlighted for all seven strains. We observe the maximum number of codons hit (count-18) whose RSCU 334 value is high in three strains of mild class coronaviruses 335 hCoVOC43, hCoVHKU1, and hCoVNL63 and minim 336 number of codons hit (count-9) is observed for MERSCoV. Among the highlighted, we observe only seven codons ATT, ACT, TCT, CCT, GTT, GCT and GGT, which are common for all seven strains with high RSCU value $(\geq 1.5)$. We observe a few codons, which are highly utilized (based on RSCU value), can be categorized into a different group of amino acids [34] (Figure 4). Such as five from Aliphatic group (A-GCT, GGGT, I-ATT, L-TTA, V-GTT), two from hydroxyl containing group (T-TCT, S-ACT), one from Basic amino acid group (R-AGA, R- CGT) and one from Cyclic group (P-CCT). Out of those seven highly common usage codons, four are from Aliphatic group (I-ATT, V-GTT, A-GCT, G-GGT), one from Cyclic group (P$\mathrm{CCT}$ ) and one from Sulfur-containing group (T-ACT) [34].

To understand the evolutionary mechanism, we consider RSCU values as a feature vector. We obtain average RSCU value for each codon within the multiple sequences of the same strain and obtain a strainwise 59-dimensional feature vector. We perform hierarchical clustering (dendogram) with the 'average' linkage method, and the obtain graph is shown in Figure5. It is observed that the severe and mild class coronaviruses are in different clades. However, hCoVOC43 and $\mathrm{hCoV} 229 \mathrm{E}$ are very close to those of the severe class coronaviruses. This is an indication of similar codon usage patterns that might be a good indicator of findings difference.

\subsection{Performing correlation analysis using different in- dexing measure}

To account for the factor that might influence the low or high codon usage bias, we calculate ENC value for all seven strains. We observe mean ENC value is ranging from 36.40 (for hCoVHKU1) to 49.8 (for MERSCoV). An ENC value greater than 45 is considered as a lower codon usage bias. We observe mean ENC value for MERSCoV and SARSCoV is relatively higher than that of SARSCoV-2 and other coronaviruses. However, ENC values for mild class coronavirus hCoVOC43 (ENC:43.794) and hCoV229E (ENC:43.1) are much higher than that of ENC values for hCoV229E(ENC:36.4) and hCoVNL63 (ENC:37.32). The previous studies on SARSCoV and MERSCoV coronaviruses have been confirmed these findings as reported in $[35,26]$. Several other studies on different viruses have shown the usage of low codon bias for influenza A virus [36], Classical swine fever virus[37] and high codon bias for Hepatitis A virus [38]. Further, that might influence the low codon usage bias, and we analyzed the relationship between the ENC value and 


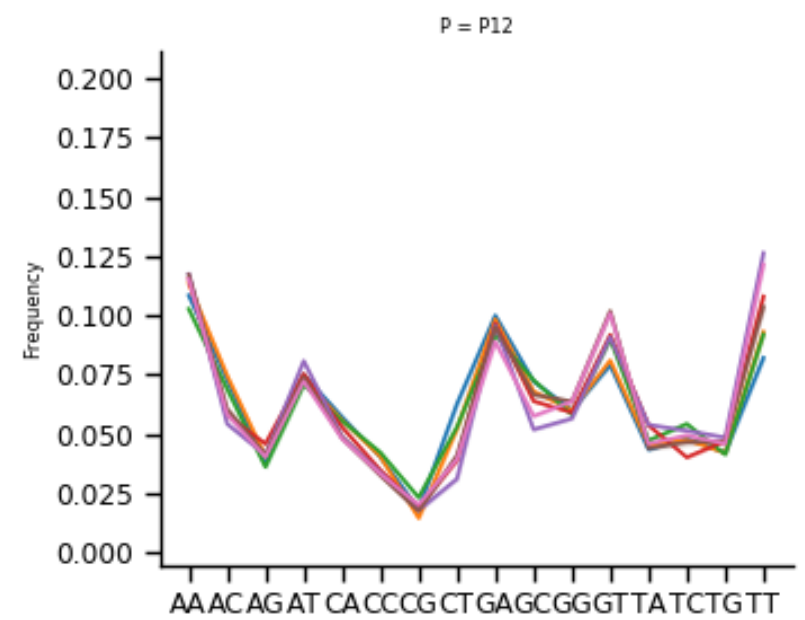

DN

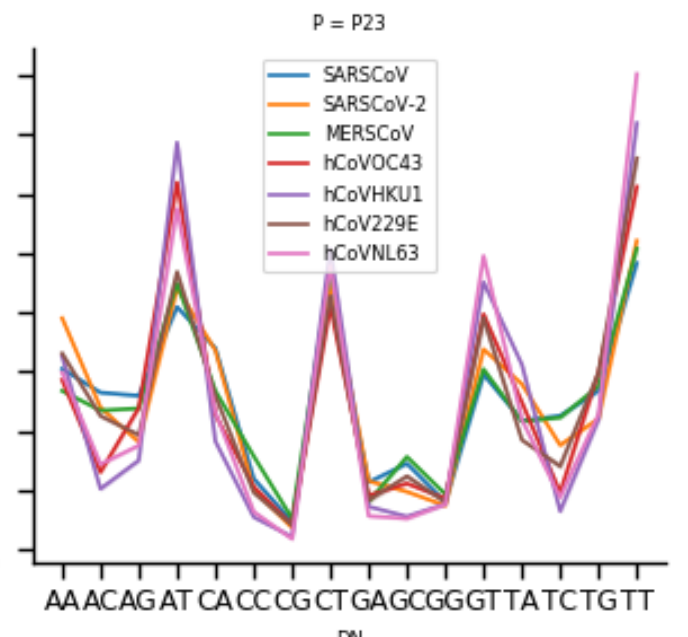

DN

Figure 2: Distribution of average di-nucleotide variability for seven strains of human coronaviruses.

Table 2: The top two high and low usage dinucleotide odd ratio value for the both combination of codon positions: P12 and P23.

\begin{tabular}{|c|c|c|c|c|c|c|c|c|}
\hline & \multicolumn{8}{|c|}{ Codon position: P12 } \\
\hline & \multicolumn{4}{|c|}{ high } & \multicolumn{4}{|c|}{ low } \\
\hline Strains & DN & Value & DN & Value & $\mathrm{DN}$ & Value & DN & Value \\
\hline SARSCoV & $\mathrm{GC}$ & 1.50 & GA & 1.41 & $\mathrm{AG}$ & 0.53 & $\mathrm{CG}$ & 0.38 \\
\hline SARSCoV-2 & GC & 1.48 & GA & 1.39 & TA & 0.56 & CG & 0.31 \\
\hline MERSCoV & GC & 1.49 & GT & 1.41 & AG & 0.53 & CG & 0.47 \\
\hline hCoVOC43 & GC & 1.55 & TT & 1.36 & AG & 0.62 & $\mathrm{CG}$ & 0.47 \\
\hline hCoVHKU1 & $\mathrm{GC}$ & 1.40 & GA & 1.37 & $\mathrm{TA}$ & 0.58 & $\mathrm{CG}$ & 0.48 \\
\hline hCoV229E & GC & 1.55 & GT & 1.46 & AG & 0.56 & CG & 0.40 \\
\hline \multirow[t]{2}{*}{ hCoVNL63 } & GC & 1.41 & GT & 1.41 & TA & 0.53 & $\mathrm{CG}$ & 0.49 \\
\hline & \multicolumn{8}{|c|}{ Codon position: P23 } \\
\hline SARSCoV & CA & 1.46 & $\mathrm{AG}$ & 1.45 & TA & 0.56 & $\mathrm{CG}$ & 0.34 \\
\hline SARSCoV-2 & GT & 1.60 & $\mathrm{CT}$ & 1.59 & $\mathrm{TC}$ & 0.62 & $\mathrm{CG}$ & 0.33 \\
\hline MERSCoV & CT & 1.49 & AG & 1.45 & GA & 0.49 & $\mathrm{CG}$ & 0.37 \\
\hline hCoVOC43 & CT & 1.63 & GT & 1.43 & CG & 0.40 & $\mathrm{TC}$ & 0.38 \\
\hline hCoVHKU1 & CT & 2.12 & GT & 1.75 & CG & 0.29 & $\mathrm{TC}$ & 0.27 \\
\hline hCoV229E & CT & 1.51 & GT & 1.51 & GA & 0.49 & $\mathrm{CG}$ & 0.36 \\
\hline hCoVNL63 & CT & 1.83 & GT & 1.83 & $\mathrm{TC}$ & 0.34 & $\mathrm{CG}$ & 0.21 \\
\hline
\end{tabular}

Table 3: GC content variability- mean and std. for each position of GC content for seven strains of coronaviruses.

\begin{tabular}{l|ll|ll|ll|ll}
\hline \multirow{2}{*}{ Strains } & GC1 & & GC2 & & GC3 & GC & \\
\cline { 2 - 9 } SARSCoV & mean & std & mean & std & mean & std & mean & std \\
SARSCoV-2 & 0.4700 & 0.0018 & 0.3918 & 0.0009 & 0.3520 & 0.0034 & 0.4113 & 0.0017 \\
MERSCoV & 0.4860 & 0.0011 & 0.3876 & 0.0025 & 0.2818 & 0.0038 & 0.3796 & 0.0021 \\
hCoV229E & 0.4667 & 0.0014 & 0.3750 & 0.0059 & 0.2987 & 0.0088 & 0.3802 & 0.0046 \\
hCoVHKU1 & 0.4262 & 0.0035 & 0.3546 & 0.0025 & 0.1854 & 0.0020 & 0.3220 & 0.0009 \\
hCoVNL63 & 0.4514 & 0.0012 & 0.3678 & 0.0016 & 0.2105 & 0.0034 & 0.3433 & 0.0013 \\
hCoVOC43 & 0.4569 & 0.0020 & 0.3676 & 0.0026 & 0.2769 & 0.0026 & 0.3669 & 0.0014 \\
\hline
\end{tabular}


bioRxiv preprint doi: https://doi.org/10.1101/2020.07.28.224386; this version posted July 28, 2020. The copyright holder for this preprint (which was not certified by peer review) is the author/funder, who has granted bioRxiv a license to display the preprint in perpetuity. It is made available under aCC-BY 4.0 International license.
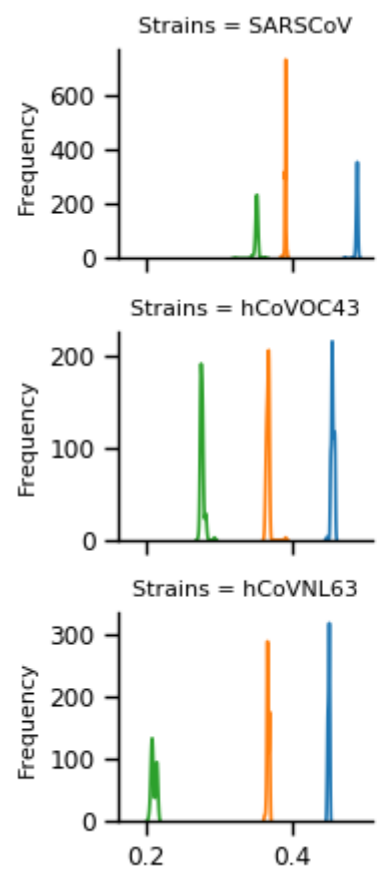

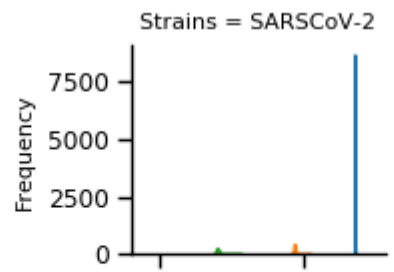

Strains $=$ hCoVHKU1

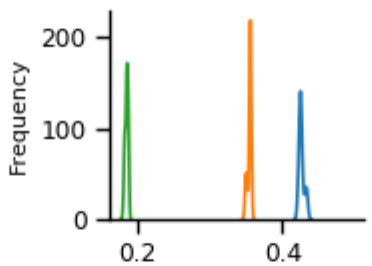

Position

$-G \mathrm{Cl}$

$-G C 2$

(a)

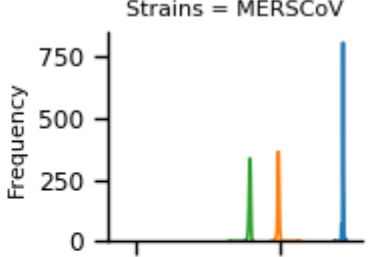

Strains $=\mathrm{hCoV} 229 \mathrm{E}$

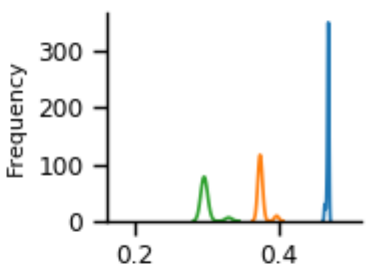

Figure 3: Distribution in position wise (first-GC1, second-GC2, third-GC3, and first and second combined-GC12) GC-content composition for seven strains of human coronaviruses.

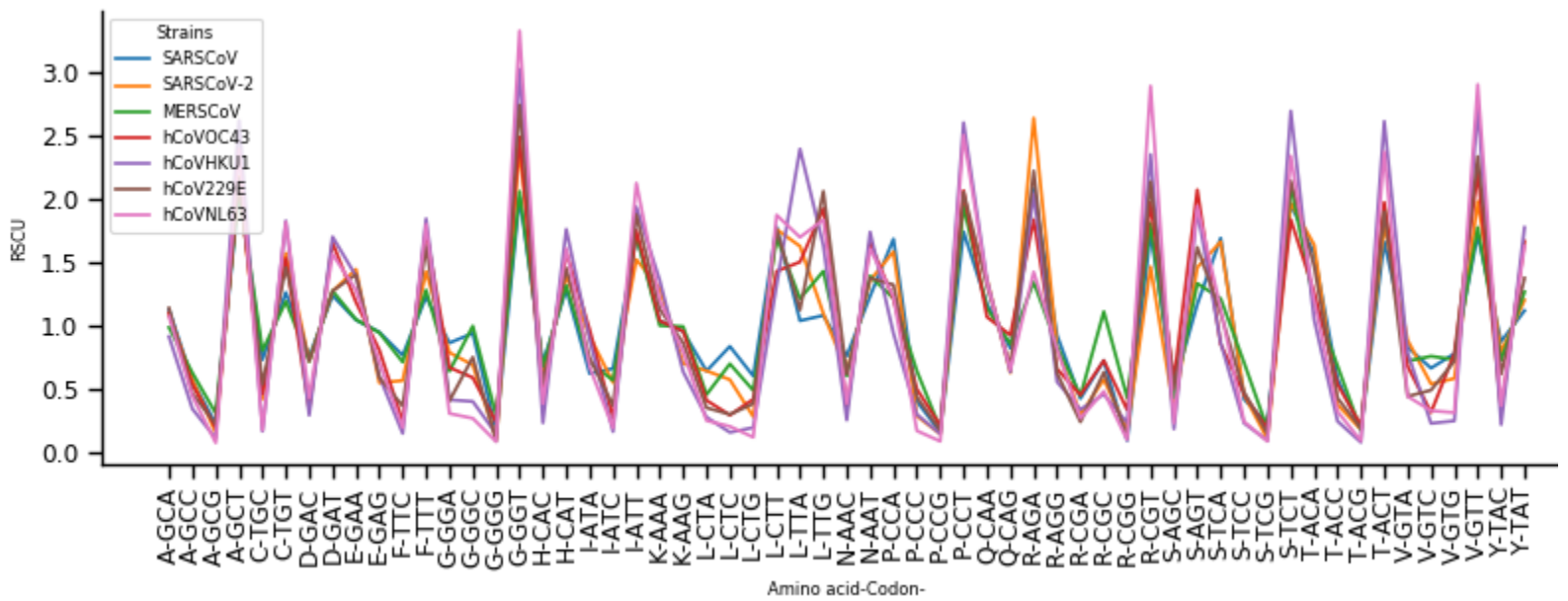

Figure 4: Distribution of RSCU value shown by amino acid with synonymous codons.

the GC-content in the third site of codons (GC3) in all ${ }_{344}$ seven strains of coronavirus genomes. In Figure 6, the 345 solid line represents the expected curve. We find all ${ }_{346}$ the proportion of points lying near to the solid line on ${ }_{347}$ the left region i.e. observed value was smaller than the ${ }_{348}$ expected value. These findings suggest that mutational ${ }_{349}$ bias might have a role in determining the codon usage ${ }_{350}$ variation. Therefore, the codon usage bias for severe class coronaviruses is relatively low, hence low codon usage bias. This study has also confirmed the additional role of dinucleotide abundance for the evolution of severe class coronaviruses.

In synonymous codons, only the last nucleotide is different (except two codons of each Arginine and Serine 
bioRxiv preprint doi: https://doi.org/10.1101/2020.07.28.224386; this version posted July 28, 2020. The copyright holder for this preprint (which was not certified by peer review) is the author/funder, who has granted bioRxiv a license to display the preprint in perpetuity. It is made available under aCC-BY 4.0 International license.

Table 4: Relative synonymous codon usage (RSCU) analysis of the various codons of all coding sequences combined in seven strains of coronaviruses. AA-Amino acid, Highlighted cells are those with RSCU value> 1.5 .

\begin{tabular}{|c|c|c|c|c|c|c|c|c|}
\hline A A & Codon & SARSCoV & SARSCoV-2 & MERSCoV & hCoVOC43 & hCoVHKU 1 & hCoV229E & hCoVNL63 \\
\hline $\mathrm{K}$ & AAA & 1.042 & 1.295 & 1.004 & 1.041 & 1.36 & 1.133 & 1.203 \\
\hline $\mathrm{N}$ & AAT & 1.236 & 1.36 & 1.395 & 1.659 & 1.742 & 1.379 & 1.611 \\
\hline $\mathrm{N}$ & AAC & 0.764 & 0.64 & 0.605 & 0.341 & 0.258 & 0.621 & 0.389 \\
\hline $\mathrm{K}$ & AAG & 0.958 & 0.705 & 0.996 & 0.959 & 0.64 & 0.867 & 0.797 \\
\hline I & ATA & 0.625 & 0.921 & 0.711 & 0.97 & 0.892 & 0.748 & 0.676 \\
\hline I & ATT & 1.71 & 1.525 & 1.718 & 1.756 & 1.94 & 1.878 & 2.128 \\
\hline I & ATC & 0.665 & 0.554 & 0.572 & 0.274 & 0.167 & 0.373 & 0.196 \\
\hline $\mathrm{T}$ & ACA & 1.571 & 1.641 & 1.185 & 1.27 & 1.051 & 1.472 & 1.204 \\
\hline $\mathrm{T}$ & ACT & 1.664 & 1.797 & 1.952 & 1.976 & 2.616 & 1.904 & 2.376 \\
\hline $\mathrm{T}$ & ACC & 0.583 & 0.38 & 0.686 & 0.54 & 0.249 & 0.432 & 0.325 \\
\hline $\mathrm{T}$ & ACG & 0.182 & 0.183 & 0.177 & 0.214 & 0.083 & 0.192 & 0.095 \\
\hline $\mathbf{R}$ & AGA & 2.082 & 2.642 & 1.347 & 1.84 & 2.046 & 2.224 & 1.427 \\
\hline $\mathrm{S}$ & AGT & 1.172 & 1.463 & 1.336 & 2.075 & 1.916 & 1.621 & 1.947 \\
\hline $\mathrm{S}$ & AGC & 0.523 & 0.335 & 0.437 & 0.575 & 0.188 & 0.504 & 0.236 \\
\hline $\mathrm{R}$ & AGG & 0.927 & 0.831 & 0.842 & 0.663 & 0.56 & 0.628 & 0.823 \\
\hline $\mathrm{Y}$ & TAT & 1.122 & 1.205 & 1.27 & 1.669 & 1.778 & 1.378 & 1.629 \\
\hline $\mathrm{Y}$ & TAC & 0.878 & 0.795 & 0.73 & 0.331 & 0.222 & 0.622 & 0.371 \\
\hline L & TTA & 1.042 & 1.63 & 1.216 & 1.506 & 2.397 & 1.127 & 1.701 \\
\hline F & TTT & 1.231 & 1.43 & 1.284 & 1.752 & 1.847 & 1.63 & 1.802 \\
\hline F & TTC & 0.769 & 0.57 & 0.716 & 0.248 & 0.153 & 0.37 & 0.198 \\
\hline L & TTG & 1.084 & 1.099 & 1.433 & 1.928 & 1.637 & 2.064 & 1.838 \\
\hline $\mathrm{S}$ & TCA & 1.694 & 1.666 & 1.217 & 0.858 & 0.869 & 1.102 & 1.136 \\
\hline $\mathrm{S}$ & TCT & 1.959 & 1.971 & 2.11 & 1.84 & 2.697 & 2.146 & 2.343 \\
\hline $\mathrm{S}$ & TCC & 0.423 & 0.458 & 0.712 & 0.463 & 0.234 & 0.479 & 0.246 \\
\hline $\mathrm{S}$ & TCG & 0.229 & 0.108 & 0.189 & 0.189 & 0.097 & 0.149 & 0.091 \\
\hline C & TGT & 1.265 & 1.575 & 1.194 & 1.534 & 1.83 & 1.462 & 1.821 \\
\hline C & TGC & 0.735 & 0.425 & 0.806 & 0.466 & 0.17 & 0.538 & 0.179 \\
\hline Q & CAA & 1.174 & 1.368 & 1.141 & 1.072 & 1.363 & 1.32 & 1.344 \\
\hline $\mathrm{H}$ & CAT & 1.29 & 1.396 & 1.32 & 1.581 & 1.764 & 1.457 & 1.612 \\
\hline $\mathrm{H}$ & CAC & 0.71 & 0.604 & 0.68 & 0.419 & 0.236 & 0.543 & 0.388 \\
\hline Q & CAG & 0.826 & 0.632 & 0.859 & 0.928 & 0.637 & 0.68 & 0.656 \\
\hline L & CTA & 0.645 & 0.647 & 0.459 & 0.414 & 0.281 & 0.355 & 0.254 \\
\hline L & CTT & 1.782 & 1.763 & 1.698 & 1.433 & 1.324 & 1.764 & 1.876 \\
\hline L & CTC & 0.84 & 0.577 & 0.702 & 0.297 & 0.161 & 0.303 & 0.208 \\
\hline L & CTG & 0.606 & 0.285 & 0.492 & 0.423 & 0.199 & 0.387 & 0.123 \\
\hline $\mathbf{P}$ & CCA & 1.687 & 1.587 & 1.219 & 1.214 & 0.943 & 1.326 & 1.229 \\
\hline $\mathrm{P}$ & CCT & 1.744 & 1.973 & 1.945 & 2.069 & 2.605 & 2.057 & 2.506 \\
\hline P & $\mathrm{CCC}$ & 0.406 & 0.29 & 0.646 & 0.503 & 0.303 & 0.441 & 0.174 \\
\hline P & $\mathrm{CCG}$ & 0.162 & 0.149 & 0.19 & 0.214 & 0.149 & 0.176 & 0.091 \\
\hline $\mathrm{R}$ & CGA & 0.428 & 0.3 & 0.449 & 0.455 & 0.342 & 0.244 & 0.272 \\
\hline $\mathrm{R}$ & CGT & 1.739 & 1.469 & 1.813 & 1.977 & 2.354 & 2.14 & 2.894 \\
\hline $\mathrm{R}$ & CGC & 0.727 & 0.579 & 1.114 & 0.728 & 0.462 & 0.635 & 0.485 \\
\hline $\mathrm{R}$ & CGG & 0.097 & 0.18 & 0.435 & 0.338 & 0.236 & 0.129 & 0.1 \\
\hline E & GAA & 1.048 & 1.448 & 1.052 & 1.189 & 1.395 & 1.407 & 1.284 \\
\hline D & GAT & 1.241 & 1.275 & 1.277 & 1.657 & 1.704 & 1.277 & 1.567 \\
\hline D & GAC & 0.759 & 0.725 & 0.723 & 0.343 & 0.296 & 0.723 & 0.433 \\
\hline E & GAG & 0.952 & 0.552 & 0.948 & 0.811 & 0.605 & 0.593 & 0.716 \\
\hline V & GTA & 0.832 & 0.888 & 0.724 & 0.682 & 0.79 & 0.445 & 0.445 \\
\hline V & GTT & 1.718 & 1.984 & 1.778 & 2.216 & 2.726 & 2.338 & 2.906 \\
\hline V & GTC & 0.668 & 0.543 & 0.762 & 0.318 & 0.232 & 0.494 & 0.332 \\
\hline V & GTG & 0.782 & 0.586 & 0.736 & 0.785 & 0.252 & 0.723 & 0.317 \\
\hline A & GCA & 1.129 & 1.09 & 0.989 & 1.106 & 0.917 & 1.142 & 1.078 \\
\hline A & GCT & 2.069 & 2.175 & 2.069 & 2.159 & 2.622 & 2.167 & 2.395 \\
\hline A & GCC & 0.574 & 0.578 & 0.631 & 0.538 & 0.347 & 0.467 & 0.448 \\
\hline A & GCG & 0.227 & 0.157 & 0.312 & 0.197 & 0.114 & 0.225 & 0.079 \\
\hline G & GGA & 0.867 & 0.791 & 0.644 & 0.673 & 0.418 & 0.409 & 0.31 \\
\hline G & GGT & 2.015 & 2.403 & 2.063 & 2.492 & 3.028 & 2.745 & 3.33 \\
\hline G & GGC & 0.943 & 0.693 & 1 & 0.593 & 0.405 & 0.754 & 0.272 \\
\hline G & GGG & 0.175 & 0.112 & 0.293 & 0.242 & 0.149 & & \\
\hline
\end{tabular}

amino acid), and the amino acid remained unchanged. 360 So, the changes of the nucleotide at the third position, it ${ }_{361}$ is indicative of a mutational force only. Only when nu- 362 cleotide change at the $2 \mathrm{nd}$ and third position of codons, 363 it leads to selection force. Towards understanding this 364 fact, we next perform a linear regression analysis for 365 GC-content at third i.e., GC3 with the GC-content at ${ }_{366}$ first position (GC1) and the second position (GC2), and ${ }_{367}$ taking both i.e., GC12. First, we show the distribution ${ }_{368}$ of average GC-content for seven strains of human coronaviruses (Figure 7(a)), From the figure, we observe various overlapping region between SARSCoV-2 and hCoV229E, and SARSCoV and MERSCoV, identifying similar GC-content pattern. It can also observe that position-wise distribution can varying among strains (Figure 7(b)). GC content at the third position of codons (GC3) is a putative indicator of the extent of base composition. Therefore, we perform a linear regression 

made available under aCC-BY 4.0 International license.

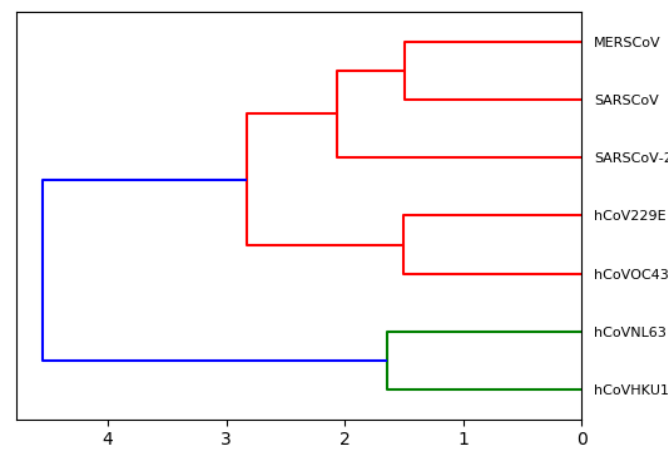

Figure 5: Hierarchical clustering of all seven strains of human coronaviruses using RSCU vector.

analysis, GC3 with GC12, GC1 and GC2. The neutrality plot analysis of GC3 against GC1/GC2/GC12 for 418 all seven strains of coronaviruses is shown in Figure 8. The solid line in the figure represents the regression line. ${ }^{419}$ The detail of the regression line with significant statisti- ${ }_{420}^{420}$ cal p-value, and $R^{2}$ value is shown in Table 5. The slope ${ }_{422}$ of the regression line suggests that the relative neutral- ${ }^{423}$ ity (mutation pressure) for $\mathrm{GC} 1 / \mathrm{GC} 2 / \mathrm{GC} 12$ and that the ${ }^{424}$ relative constraint on the GC3 (natural selection). It is ${ }_{426}^{425}$ observed that there a strong correlation between GC2 ${ }_{427}$ and GC3 both for SARSCoV-2 $\left(R^{2}=0.96, p<0.001\right){ }^{428}$ and hCoV229E $\left(R^{2}=0.97, p<0.001\right)$ and a moder- ${ }^{429}$ ate correlation for hCoVNL63 $\left(R^{2}=0.81, p<0.001\right) .{ }_{431}{ }_{430}$ In comparing $\mathrm{GC} 3$ and $\mathrm{GC} 1$, we observe comparatively ${ }_{432}$ low correlation, hCoV229E $\left(R^{2}=0.70, p<0.001\right){ }^{433}$ hCoVNL63 $\left(R^{2}=0.48, p<0.001\right)$ and SARSCoV ${ }^{434}$ $\left(R^{2}=0.37, p<0.001\right)$. If there is a correlation between ${ }^{435}$ the GC12 and GC3 that is codon bias is present at all ${ }_{437}$ the codon positions, and this is likely to be due to mu- ${ }^{438}$ tational forces that influencing codon bias [39]. When ${ }_{440}^{439}$ comparing GC3 with GC12, we observe strong correla- ${ }_{441}^{440}$ tion for SARSCoV-2 and hCoV229E (Table 5). Above ${ }_{442}$ mentioned highlighted points, only for hCoV229E, we ${ }^{443}$ observe negative correlation (GC3 Vs. GC1).

\section{Conclusion}

In this work, we performed an extensive analytical ${ }_{450}^{49}$ and exploratory study on the genome sequence of seven ${ }_{451}$ human coronavirus species. We reported significant fea- ${ }^{452}$ tures for all candidate coronaviruses that are common ${ }^{453}$ and distinct. We observed that overall GC-content in ${ }^{454}$ codon position 3rd (GC3) is playing a crucial role in ${ }^{455}$ differentiating strains. We further showed that the high ${ }^{457}$ usage of GC (Strong group) dinucleotide in the first ${ }^{458}$ two positions of codons and CT (Week group) dinu- ${ }_{460}^{459}$ cleotide in the last two locations (P23) of codons. In ${ }_{461}$ terms of the synonymous codon usage pattern, we reported a high degree of similarity among mild class human coronaviruses. Among severe class, a shallow usage pattern observed for MERSCoV. These codons mostly belong to Aliphatic and Hydroxyl amino acid group. A phylogenetic tree built using RSCU feature reveals proximity among hCoVOC43 and hCoV229E (mild). We observed a strong correlation (significant p-value) between GC2 and GC3 for SARSCoV2, hCoV229E and hCoVNL63, and between GC1 and GC3 for hCoV229E, hCoVNL63, SARSCoV. We believe that our findings will help in understanding the mechanism of the mutation in the host and viral genes and its consequence across the human coronavirus.

\section{References}

[1] P. C. Woo, S. K. Lau, C. S. Lam, C. C. Lau, A. K. Tsang, J. H. Lau, R. Bai, J. L. Teng, C. C. Tsang, M. Wang, et al., Discovery of seven novel mammalian and avian coronaviruses in the genus deltacoronavirus supports bat coronaviruses as the gene source of alphacoronavirus and betacoronavirus and avian coronaviruses as the gene source of gammacoronavirus and deltacoronavirus, Journal of virology 86 (2012) 3995-4008.

[2] S. Perlman, J. Netland, Coronaviruses post-sars: update on replication and pathogenesis, Nature reviews microbiology 7 (2009) 439-450.

[3] J. Peiris, S. Lai, L. Poon, Y. Guan, L. Yam, W. Lim, J. Nicholls, W. Yee, W. Yan, M. Cheung, et al., Coronavirus as a possible cause of severe acute respiratory syndrome, The Lancet 361 (2003) 1319-1325.

[4] R. J. de Groot, S. C. Baker, R. S. Baric, C. S. Brown, C. Drosten, L. Enjuanes, R. A. Fouchier, M. Galiano, A. E. Gorbalenya, Z. A. Memish, et al., Commentary: Middle east respiratory syndrome coronavirus (mers-cov): announcement of the coronavirus study group, Journal of virology 87 (2013) 7790-7792.

[5] A. Chafekar, B. C. Fielding, Mers-cov: understanding the latest human coronavirus threat, Viruses 10 (2018) 93.

[6] L. E. Gralinski, V. D. Menachery, Return of the coronavirus: 2019-ncov, Viruses 12 (2020) 135.

[7] Y. Ruan, C. L. Wei, A. E. Ling, V. B. Vega, H. Thoreau, S. Y. S. Thoe, J.-M. Chia, P. Ng, K. P. Chiu, L. Lim, et al., Comparative full-length genome sequence analysis of 14 sars coronavirus isolates and common mutations associated with putative origins of infection, The Lancet 361 (2003) 1779-1785.

[8] M. Cascella, M. Rajnik, A. Cuomo, S. C. Dulebohn, R. Di Napoli, Features, evaluation and treatment coronavirus (covid-19), in: Statpearls [internet], StatPearls Publishing, 2020.

[9] E. Tabor, Emerging viruses in human populations, Elsevier, 2006.

[10] J. Lei, Y. Kusov, R. Hilgenfeld, Nsp3 of coronaviruses: Structures and functions of a large multi-domain protein, Antiviral research 149 (2018) 58-74.

[11] W. Song, M. Gui, X. Wang, Y. Xiang, Cryo-em structure of the sars coronavirus spike glycoprotein in complex with its host cell receptor ace2, PLoS pathogens 14 (2018) e1007236.

[12] S. Osawa, T. H. Jukes, K. Watanabe, A. Muto, Recent evidence for evolution of the genetic code., Microbiology and Molecular Biology Reviews 56 (1992) 229-264. 


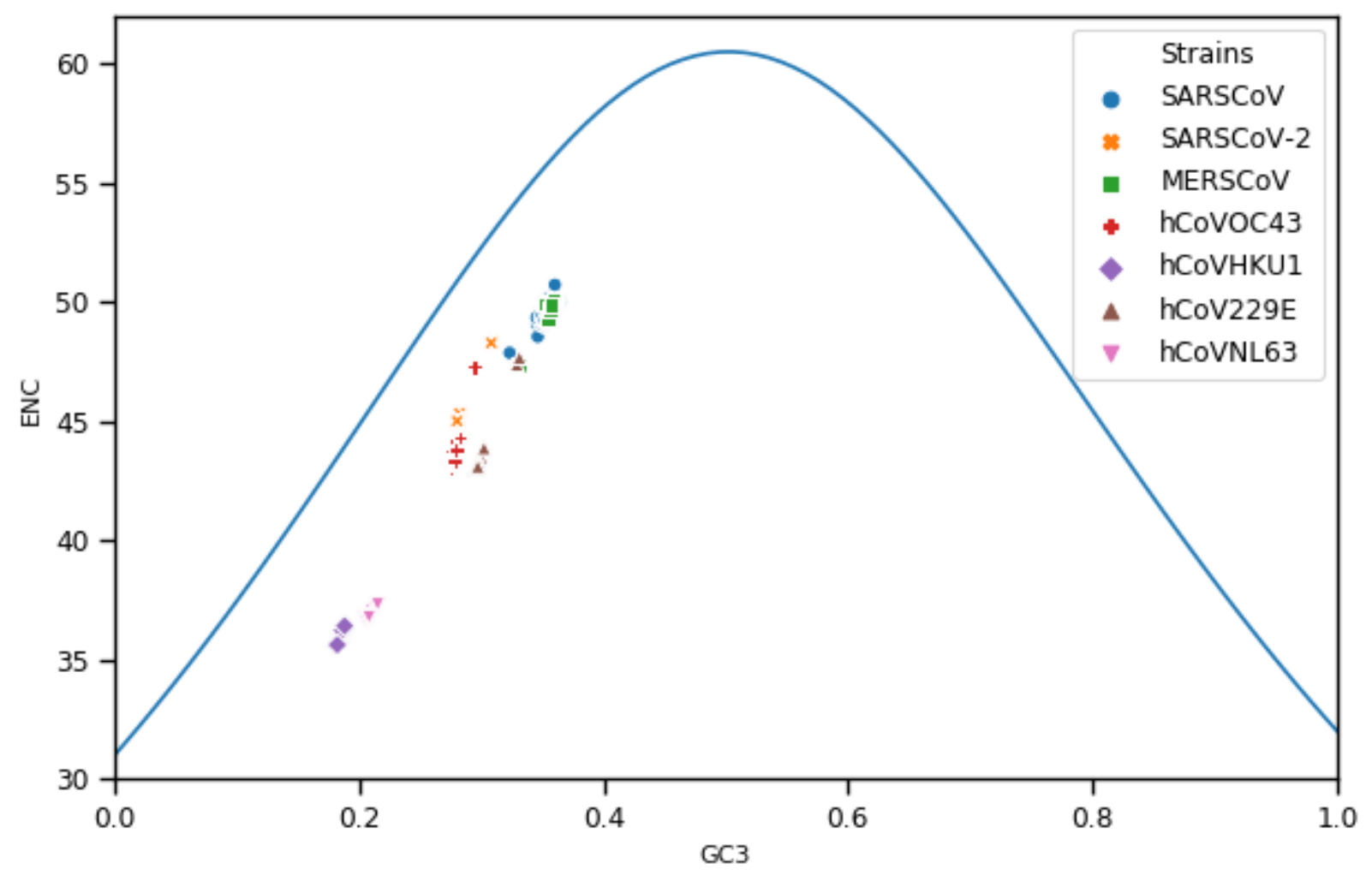

Figure 6: The plots of ENC values against GC3s values for all seven strains shown by different colors and style.

[13] S. Herlitze, M. Koenen, A general and rapid mutagenesis 491 method using polymerase chain reaction, Gene 91 (1990) 143- 492 147.

14] V. D. Menachery, K. Debbink, R. S. Baric, Coronavirus non- 494 structural protein 16: evasion, attenuation, and possible treat- 495 ments, Virus research 194 (2014) 191-199.

[15] M. C. Zambon, The pathogenesis of influenza in humans, Re- 497 views in medical virology 11 (2001) 227-241.

[16] P. J. Walker, J. A. Cowley, Viral genetic variation: implications 499 for disease diagnosis and detection of shrimp pathogens, FAO 500 fisheries. Technical paper (2000) 54-9.

17] R. Grantham, C. Gautier, M. Gouy, R. Mercier, A. Pave, Codon 502 catalog usage and the genome hypothesis, Nucleic acids re- 503 search 8 (1980) 197-197.

[18] R. J. Grocock, P. M. Sharp, Synonymous codon usage in cryp- 505 tosporidium parvum: identification of two distinct trends among 506 genes, International journal for parasitology 31 (2001) 402-412. 507

[19] R. Khandia, S. Singhal, U. Kumar, A. Ansari, R. Tiwari, 508 K. Dhama, J. Das, A. Munjal, R. K. Singh, Analysis of nipah 509 virus codon usage and adaptation to hosts, Frontiers in microbi- 510 ology 10 (2019) 886.

[20] I. S. Belalov, A. N. Lukashev, Causes and implications of codon 512 usage bias in rna viruses, PloS one 8 (2013) e56642.

[21] P. Auewarakul, Composition bias and genome polarity of rna 514 viruses, Virus research 109 (2005) 33-37.

22] R. Klitting, E. A. Gould, X. De Lamballerie, G+ c content 516 differs in conserved and variable amino acid residues of fla- 517 viviruses and other evolutionary groups, Infection, Genetics and 518 Evolution 45 (2016) 332-340.
[23] J. B. Plotkin, G. Kudla, Synonymous but not the same: the causes and consequences of codon bias, Nature Reviews Genetics 12 (2011) 32-42.

[24] P. M. Sharp, L. R. Emery, K. Zeng, Forces that influence the evolution of codon bias, Philosophical Transactions of the Royal Society B: Biological Sciences 365 (2010) 1203-1212.

[25] Z. Zhao, H. Li, X. Wu, Y. Zhong, K. Zhang, Y.-P. Zhang, E. Boerwinkle, Y.-X. Fu, Moderate mutation rate in the sars coronavirus genome and its implications, BMC evolutionary biology 4 (2004) 21.

[26] Y. Chen, Q. Xu, X. Yuan, X. Li, T. Zhu, Y. Ma, J.-L. Chen, Analysis of the codon usage pattern in middle east respiratory syndrome coronavirus, Oncotarget 8 (2017) 110337.

[27] J. D. Ramirez, M. Munoz, C. Hernandez, C. Florez, S. Gomez, A. Rico, L. Pardo, E. C. Barros, A. Paniz-Mondolfi, Genetic diversity among sars-cov2 strains in south america may impact performance of molecular detection, medRxiv (2020).

[28] M. C. Rahalkar, R. A. Bahulikar, Understanding the origin of 'batcovratg13', a virus closest to sars-cov-2 (2020).

[29] K. G. Andersen, A. Rambaut, W. I. Lipkin, E. C. Holmes, R. F. Garry, The proximal origin of sars-cov-2, Nature medicine 26 (2020) 450-452.

[30] D. Kunec, N. Osterrieder, Codon pair bias is a direct consequence of dinucleotide bias, Cell reports 14 (2016) 55-67.

[31] P. M. Sharp, W.-H. Li, An evolutionary perspective on synonymous codon usage in unicellular organisms, Journal of molecular evolution 24 (1986) 28-38.

[32] P. M. Sharp, T. M. Tuohy, K. R. Mosurski, Codon usage in yeast: cluster analysis clearly differentiates highly and lowly expressed 


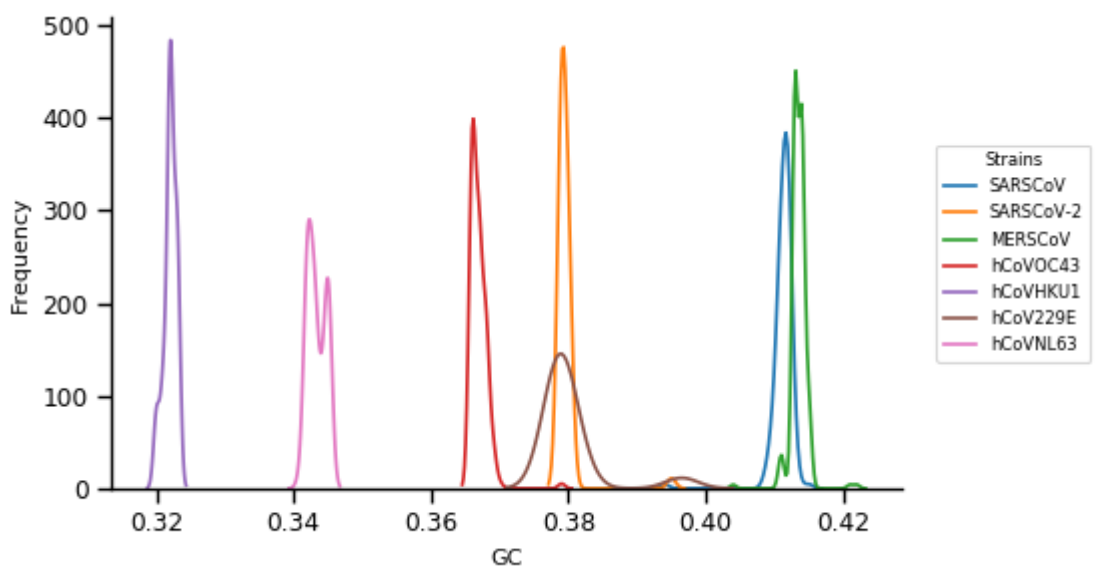

(a)
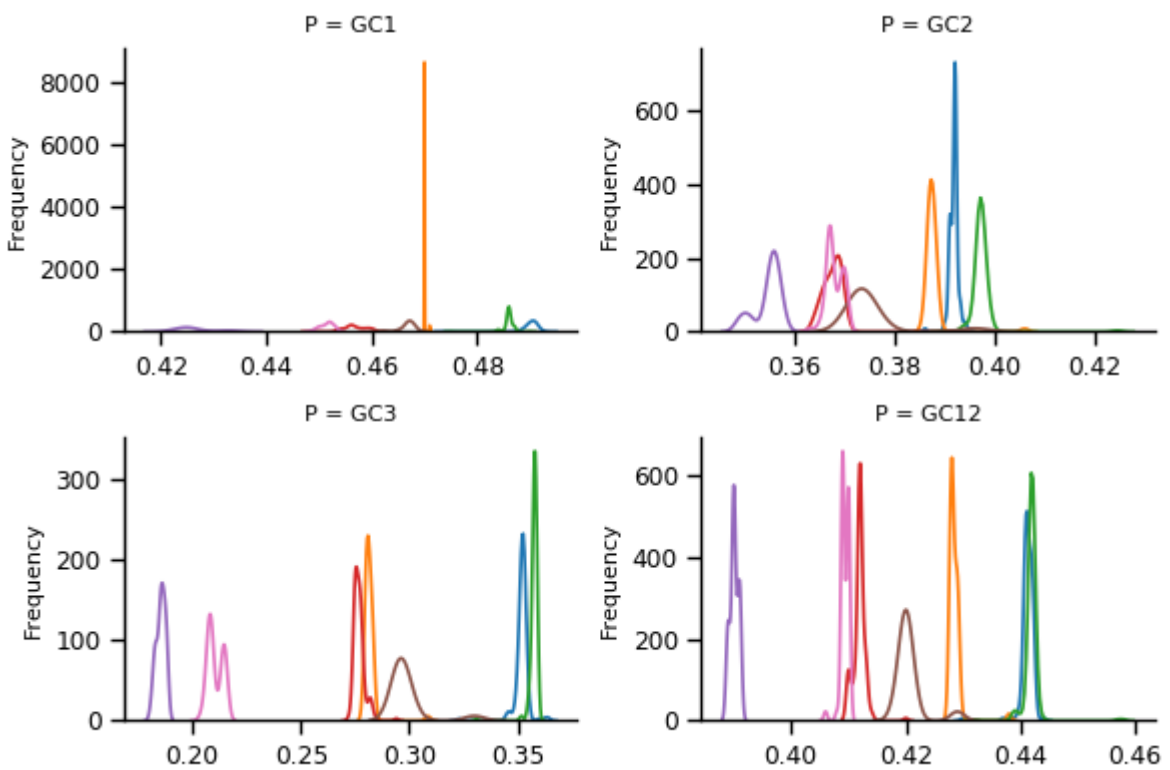

(b)

Figure 7: (a) Distribution of GC-content composition for seven strains of human coronaviruses. (b) Position wise distribution of GC-content (first-GC1,second-GC2,third-GC3 and first and second in combined-GC12) in seven strains of human coronaviruses.

genes, Nucleic acids research 14 (1986) 5125-5143.

[33] F. Wright, The 'effective number of codons' used in a gene, 5304 Gene 87 (1990) 23-29.

[34] J. K. Das, P. Das, K. K. Ray, P. P. Choudhury, S. S. Jana, Math- 596 ematical characterization of protein sequences using patterns 537 as chemical group combinations of amino acids, PloS one 11538 (2016) e0167651.

[35] W. Gu, T. Zhou, J. Ma, X. Sun, Z. Lu, Analysis of synony- 540 mous codon usage in sars coronavirus and other viruses in the 541 nidovirales, Virus research 101 (2004) 155-161.

[36] P. Auewarakul, S. Chatsurachai, A. Kongchanagul, P. Kanrai, 543 S. Upala, P. Suriyaphol, P. Puthavathana, Codon volatility of hemagglutinin genes of h5n1 avian influenza viruses from dif- ferent clades, Virus genes 38 (2009) 404-407.

[37] P. Tao, L. Dai, M. Luo, F. Tang, P. Tien, Z. Pan, Analysis of synonymous codon usage in classical swine fever virus, Virus genes 38 (2009) 104-112.

[38] G. Moratorio, A. Iriarte, P. Moreno, H. Musto, J. Cristina, A detailed comparative analysis on the overall codon usage patterns in west nile virus, Infection, Genetics and Evolution 14 (2013) 396-400.

[39] G. M. Jenkins, E. C. Holmes, The extent of codon usage bias in human rna viruses and its evolutionary origin, Virus research 92 (2003) 1-7. 
bioRxiv preprint doi: https://doi.org/10.1101/2020.07.28.224386; this version posted July 28, 2020. The copyright holder for this preprint (which was not certified by peer review) is the author/funder, who has granted bioRxiv a license to display the preprint in perpetuity. It is made available under aCC-BY 4.0 International license.
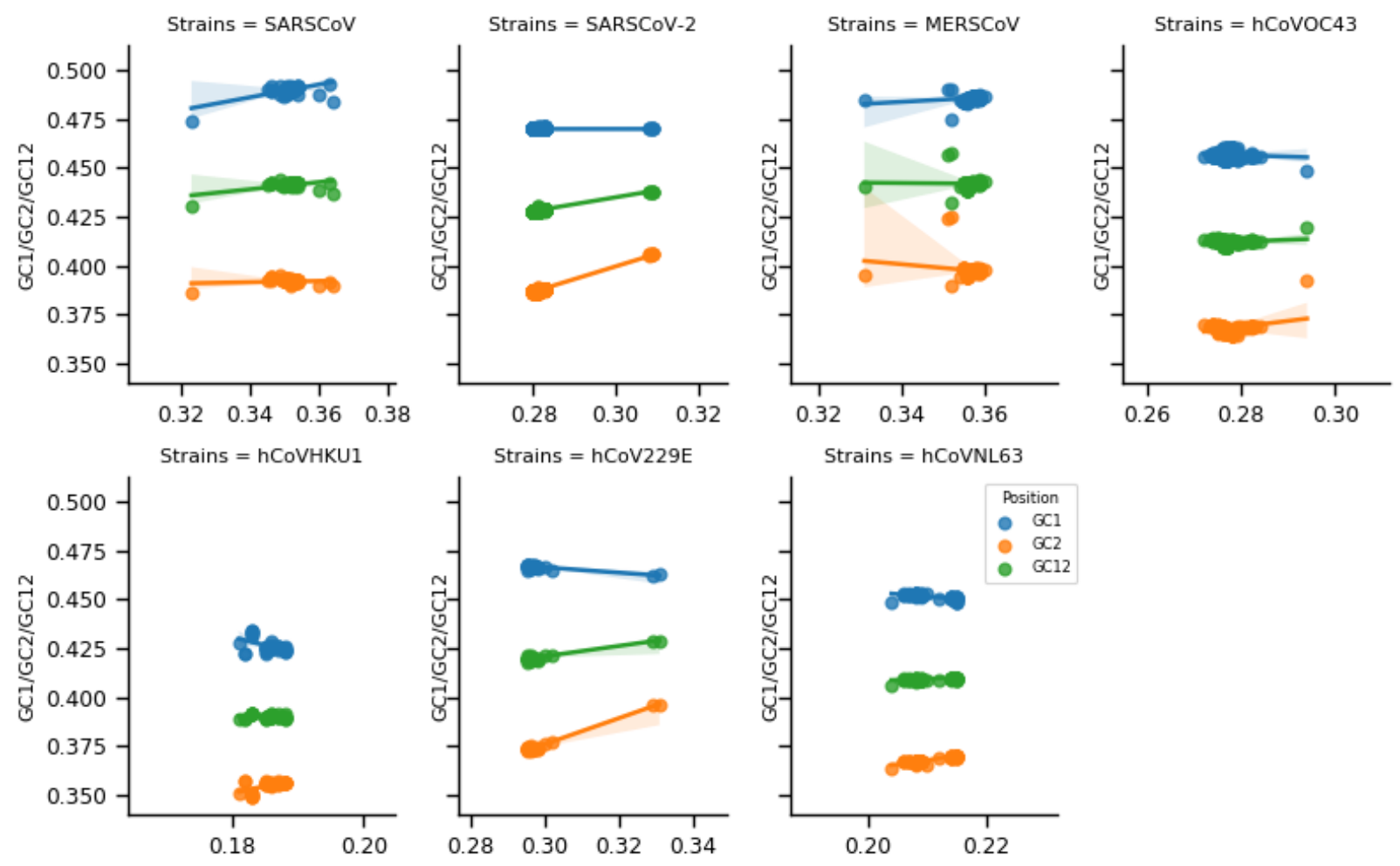

(a)

Figure 8: The neutral analysis of $\mathrm{GC} 3$ against $\mathrm{GC1} / \mathrm{GC} 2 / \mathrm{GC} 12$ for all seven strains of coronaviruses. The solid line represents the regression line. 
bioRxiv preprint doi: https://doi.org/10.1101/2020.07.28.224386; this version posted July 28, 2020. The copyright holder for this preprint (which was not certified by peer review) is the author/funder, who has granted bioRxiv a license to display the preprint in perpetuity. It is made available under aCC-BY 4.0 International license.

Table 5: Linear regression computed by comparing GC3 with GC1, GC2 and GC12 for all seven strains of coronaviruses. Calculated correlation $\left(R^{2}\right)$ and $p$-value are also shown.

\begin{tabular}{l|l|l|l|l}
\hline Strains & GC3 Vs. & Regression line & $R^{2}$ & $\mathrm{p}$-value \\
\hline SARSCoV & GC1 & $y=0.33 x+0.38$ & 0.3768 & 0.0 \\
& GC2 & $y=0.03 x+0.38$ & 0.0141 & 0.1713 \\
& GC12 & $y=0.18 x+0.38$ & 0.2521 & 0.0 \\
\hline SARSCoV-2 & GC1 & $y=0.00 x+0.47$ & 0.0005 & 0.6602 \\
& GC2 & $y=0.65 x+0.20$ & 0.9659 & 0.0 \\
& GC12 & $y=0.36 x+0.33$ & 0.9695 & 0.0 \\
\hline MERSCoV & GC1 & $y=0.12 x+0.44$ & 0.0534 & 0.0004 \\
& GC2 & $y=-0.19 x+0.46$ & 0.022 & 0.0236 \\
& GC12 & $y=-0.02 x+0.45$ & 0.0005 & 0.7275 \\
\hline hCoVOC43 & GC1 & $y=-0.08 x+0.48$ & 0.0098 & 0.2173 \\
& GC2 & $y=0.30 x+0.28$ & 0.09 & 0.0001 \\
& GC12 & $y=0.10 x+0.39$ & 0.0502 & 0.0048 \\
\hline hCoVHKU1 & GC1 & $y=-0.82 x+0.58$ & 0.2321 & 0.0039 \\
& GC2 & $y=0.72 x+0.22$ & 0.3552 & 0.0002 \\
& GC12 & $y=-0.02 x+0.39$ & 0.0022 & 0.7941 \\
\hline hCoV229E & GC1 & $y=-0.14 x+0.51$ & 0.7023 & 0.0 \\
& GC2 & $y=0.66 x+0.18$ & 0.9799 & 0.0 \\
& GC12 & $y=0.26 x+0.34$ & 0.9311 & 0.0 \\
\hline hCoVNL63 & GC1 & $y=-0.25 x+0.50$ & 0.4835 & 0.0 \\
& GC2 & $y=0.43 x+0.28$ & 0.8114 & 0.0 \\
& GC12 & $y=0.11 x+0.39$ & 0.2866 & 0.0 \\
\hline
\end{tabular}

